\title{
'N PALATOGRAFIES-FOTOGRAFIESE ONDERSOEK VAN DIE AFRIKAANSE KONSONANTKLANKE
}

\author{
H.E.C. TESNER M.A. (PRET.) \\ E.C. NAUDÉ M.A. (LOG) (PRET.) \\ Departement Spraakwetenskap, Spraakheelkunde en Oudiologie, Universiteit \\ van Pretoria.
}

\section{OPSOMMING}

Die konsonantartikulasie van een Afrikaanssprekende proefpersoon is palatografiesfotografies ondersoek om vas te stel wat die ko-artikulatoriese invloede van verskillende vokaalongewings op die artikulasiekontakpunt van besondere konsonante is. Afleidings word gemaak met betrek king tot die stabiliteit van die artikulasiepunt vir die verskillende konsonante. Die verslag word afgesluit met enkele terapeutiese riglyne en aanbevelings vir verdere navorsing.

\section{SUMMARY}

Consonant articulation of an Afrikaans-speaking subject was researched in a palatographicphotographic study in order to establish the co-articulatory effect of different vowel contexts on the place of articulation of specific consonants. Deductions are made as to the stability of place of articulation of the different consonants. Certain guidelines for therapy are given as well as suggestions for further research.

Die palatografiese tegniek is een van die oudste eksperimentele hulpmiddels tot die beskikking van die fonetikus wat artikulasie bestudeer.

Ten spyte hiervan is hierdie tegniek nog nooit uitgebreid toegepas om die invloed van variërende vokaalkontekste op die plasing vir konsonantartikulasie in Afrikaans te bestudeer nie. Dit word in die fonetiese wetenskap aanvaar dat spraak op artikulatoriese vlak streng gesproke nie segmenteerbaar is nie. Nogtans is die praktiese waarde van 'n afsonderlike beskouing van konsonantklanke goed bekend by onderwysers in die fonetiek sowel as by spraakterapeute. Meerdere kennis oor die gedrag van die artikulators vir klanke in verskillende omgewings kan ons begrip van artikulasie as 'n dinamiese proses slegs verbreed. Hierdie fisiologies-georiënteerde kennis moet tesame met 'n linguisties-georiënteerde beskouing van die distink tiewe klankeienskappe toegepas word.

\section{METODE}

Slegs een proefpersoon is by die studie betrek. Die palatum is bestuif met 'n mengsel van houtskool- en sjokoladepoeier en na elke artikulasie is 'n kleurfoto van die monddak met 'n "Polaroid CU-5 Land Camera" geneem. Die kamera is voorsien van 'n ringflits en 'n mondspieël van verchroomde staal. Hibitane is as ontsmettingsmiddel gebruik. Die konsonante wat by die studie betrek is en die klankomgewings waarin hulle geproduseer is, verskyn in Tabel I. 


\begin{tabular}{|c|c|c|c|c|}
\hline iti & itu & utu & uti & $\partial \mathrm{t} \partial$ \\
\hline idi & idu & udu & udi & $\partial \mathrm{do}$ \\
\hline ili & ilu & ulu & uli & $\partial 1 \partial$ \\
\hline ini & inu & unu & uni & ənə \\
\hline iri & & uru & uri & әг \\
\hline iri & iru & uru & urp & \\
\hline isi & isu & usu & usi & $\exists \mathrm{s} \partial$ \\
\hline izi & izu & uzu & uzi & $\partial \mathrm{z} \partial$ \\
\hline$i \int i$ & $\mathrm{i} \int u$ & $\mathrm{u} \int \mathrm{u}$ & $u \int i$ & \\
\hline ini & ini & $u_{\sqrt{ }}$ & ${ }^{1}, y^{3} \mathrm{i}$ & \\
\hline irji & i引u & uṇ! & uni & \\
\hline iki & iku & uku & uki & $\partial k \partial$ \\
\hline ixi & $i x u$ & uxu & uxi & $\partial x \partial$ \\
\hline igi & igu & ugu & ugi & $\partial \mathrm{g}$ \\
\hline ici & & & uci & $\bar{\sigma} \sigma^{2}$ \\
\hline
\end{tabular}

TABEL I. Die konsonante wat by die studie betrek is en die klankomgewings waarin hulle geproduseer is.

Die iru-kombinasie is nie in die tabel verteenwoordig nie, omdat geen bevredigende fotografiese beeld van die produksie verkry kon word nie. Verwerking van resultate: Elke foto is vir ontledingsdoeleindes onderverdeel soos in Fig. 1. Met behulp van hierdie verdeling is die volgende metings geneem:

1. Afstand van aanraking vanaf voortande.

2. Antero-posterior breedte van aanraking.

3. Unilaterale area van aanraking links.

4. Unilaterale area van aanraking regs. Voorbeelde van hierdie metings verskyn in Tabelle II en III. Bostaande metings is uit praktiese oorwegings na grafiekpapier oorgedra wat terselfdertyd 'n duideliker voorstelling van die artikulasiekontak gegee het en dit makliker gemaak het om aanrakingsareas numeries te verwerk. Hierdie metode het die kwantitatiewe vergelyking van gegewens vir verskillende klanke moontlik gemaak. (sien Grafiek 1).

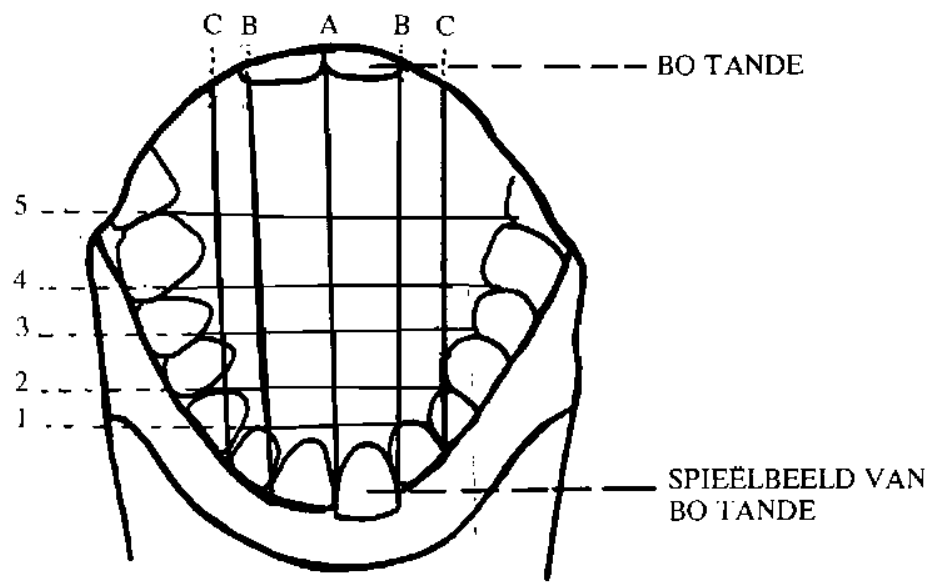

Figure 1 .

The South African Jounal of Communication Disorders, Vol. 25. 1978 


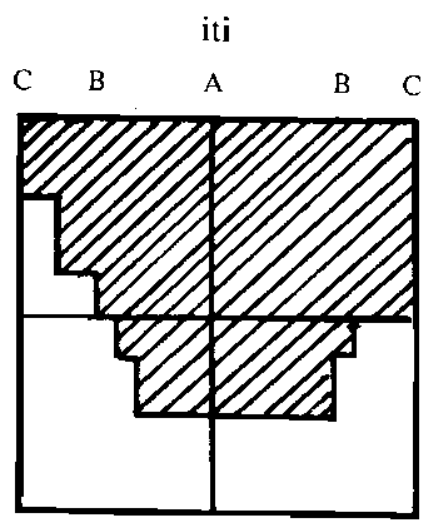

Grafiek 1

\begin{tabular}{|c|c|c|l|l|c|}
\hline $\begin{array}{c}\text { Klank- } \\
\text { ongewings }\end{array}$ & \multicolumn{1}{|c|}{$\mathrm{i}-\mathrm{i}$} & $\mathrm{i}-\mathrm{u}$ & \multicolumn{1}{|c|}{$\mathrm{u}-\mathrm{u}$} & \multicolumn{1}{|c|}{$\mathrm{u}-\mathrm{i}$} & - \\
\hline $\mathrm{t}$ & $0-1,50$ & $0-1,75$ & $0-1,50$ & $0-1,67$ & $0-2$ \\
$\mathrm{r}$ & $1,50-2$ & & $1,33-1,67$ & $1,50-1,75$ & $1,25-1,50$ \\
\hline
\end{tabular}

Verklaring: Die eerste letterwaarde vir elke klankomgewing dui op die afstand van aanraking vanaf die voortande. Die afstand tussen die twee letterwaardes vir elke klankomgewing ref́lekteer die anteroposterior breedte van die aanraking. Raadpleeg fig. 1 .

TAlBt:L 11. Afstand van aanraking vanal vourtande ell interoposterior breedte van aanraking vir $[\mathbf{t}]$ en $|\mathbf{r}|$.

\begin{tabular}{|c|c|c|c|c|}
\hline & \multicolumn{2}{|c|}{$\mathrm{i}-\mathrm{i}$} & \multicolumn{2}{|c|}{$\partial-\partial$} \\
\hline & Links & Regss & I.inks & Regs \\
\hline & $1 \mathrm{~A}$ & $1 \mathrm{~A}$ & $1 \mathrm{~A}$ & $1 \mathrm{~A}$ \\
\hline & $2 \mathrm{~B}$ & $2 \mathrm{~B}, 50$ & $2 \mathrm{~A}$ & $2 \mathrm{~A}$ \\
\hline$t$ & $3 \mathrm{~B}, 25$ & $3 \mathrm{~B}, 75$ & $3 \mathrm{~B}, 75$ & $3 \mathrm{~B}, 50$ \\
\hline & $4 \mathrm{~B}, 50$ & 4 C:50 & $4 \mathrm{C}$ & $4 C$ \\
\hline & $5 C$ & $5 \mathrm{C}, 50$ & $5 \mathrm{C}$ & $5 C, 50$ \\
\hline & $6 C$ & $6 C .50$ & $6 \mathrm{C}, 25$ & $6 \mathrm{C} 75$ \\
\hline \multirow{6}{*}{$r$} & $1 C, 50$ & $1 C, 50$ & $1 \mathrm{C}, 50$ & $1 \mathrm{C}, 50$ \\
\hline & $2 \mathrm{~A}$ & $2 \mathrm{~A}$ & 2 C. 50 & $2 \mathrm{C}, 50$ \\
\hline & $3 \mathrm{~B}, 50$ & $3 \mathrm{~B}, 50$ & $3 \mathrm{~A}, 50$ & $3 \mathrm{~A}$ \\
\hline & $4 \quad \mathrm{~B}, 25$ & $4 B, 50$ & $4 B$ & $4 \mathrm{C}$ \\
\hline & $5 \mathrm{~B}, 50$ & $5 \mathrm{C}, 25$ & $5 \mathrm{C}$ & 5 C. .50 \\
\hline & 6.- & 6. - & $6-$ & 6.- \\
\hline
\end{tabular}

TABFI. 11. Laterale aanraking.

Die standaardafwyking van die area van aanraking vir elke konsonantklank in die verskillende klankomgewings is bereken om 'n aanduiding te gee van die stabiliteit van die artikulasiekontakpunt. Dit word in Tabel IV weergegee. 


\begin{tabular}{|lc|c|}
\hline \multicolumn{2}{|c|}{ Gemiddelde } & Standaardafwyking \\
\hline t: & 34,8 & 8,37 \\
r: & 53,6 & 17,3 \\
k: & 9,6 & 3,9 \\
d: & 31,2 & 7,6 \\
s: & 71,6 & 6,4 \\
x: & 14,8 & 6,9 \\
l: & 33,8 & 9 \\
z: & 75,6 & 11,2 \\
g: & 10,8 & 5,7 \\
n: & 42 & 12,4 \\
f: & 60,4 & 19,7 \\
r: & 34,5 & 5,1 \\
g: & 14,8 & 5,5 \\
\hline
\end{tabular}

TABEL IV. Metingswaardes.

\section{BEVINDINGS}

Uit die grafieke is vir elke klank bereken watter klankomgewing die artikulasiekontakpunt die verste na voor plaas. (Sekere klanke is nie by hierdie berekenings ingesluit nie, $t . w$. die ruisklanke $[s],[z]$ en $\left[\int\right]$ asook ( $\mathrm{S} \mid \mathrm{en}[\mathrm{c}]$ ). Die klankomgewings vir elke klank is vervolgens in volgorde van voor na agter geplaas (Tabel V).

\begin{tabular}{|c|c|c|c|c|c|}
\hline$t$ & iti & utu & uti & itu & $\partial t \partial$ \\
\hline d & idu & idi & udi & $\partial d$ & udu \\
\hline 1 & ili & $\ni 1 \theta$ & ilu & uli & ulu \\
\hline$\pi$ & unu & uni & ini & əna & inu \\
\hline $\mathbf{r}$ & $\partial \mathbf{r}$ & uru & iri & uri & \\
\hline$\Gamma$ & $\partial \Gamma \partial$ & iru & usi & ifi & uru \\
\hline$n$ & $i \eta j i$ & әуコ & ungu & ingu & urji \\
\hline $\mathbf{k}$ & uki & akə & iki & uku & iku \\
\hline$x$ & ixi & $\partial x \partial$ & uxu & ixu & uxi \\
\hline $\mathrm{g}$ & igi & วgə & ugu & igu & ugi \\
\hline
\end{tabular}

TABEL $V$. Volgorde van voor na agter.

Uit Tabel $\mathrm{V}$ blyk dit duidelik dat geen konstante patroon ńa vore tree nie. 'n Kwalitatiewe ontleding van die gegewens lei tot die volgende tentatiewe gevolgtrekkings:

Die klankomgewing [i-i] blyk in die meeste gevalle vir 'n verplasing na voor verantwoordelik te wees. Daarna volg die omgewing [ə-ə]. Die omgewing $[\mathrm{u}-\mathrm{u}]$ verskuif die kontakpunt in die meeste gevalle na agter. Hier moet weer daarop gewys word dat uitsonderings voorkom wat die patroon versteur.

Wat die area van laterale kontak betref, is die klankomgewings vir elke klank weereens gerangskik in volgorde van breed na smal (Tabel VI). 


\begin{tabular}{|c|c|c|c|c|c|}
\hline $\mathbf{t}$ & iti & itu & utu & uti & ato \\
\hline d & udi & idi & idu & udu & ədə \\
\hline 1 & ilu & ulu & jli & ala & uli \\
\hline $\mathbf{n}$ & ini & uni & inu & unu & วnอ \\
\hline $\mathbf{r}$ & uri & iri & әra & uru & \\
\hline$r$ & iru & ara & ifi & uri & $\mathrm{u} C \mathrm{u}$ \\
\hline$s$ & isi & usi & $\partial s \partial$ & usu & isu \\
\hline$z$ & izu & uzi & izi & uzu & $\partial z \partial$ \\
\hline $\int$ & $i \int u$ & $\mathrm{i} \int \mathrm{i}$ & $u \int i$ & $u \int u$ & $\partial \sqrt{\partial}$ \\
\hline $\mathrm{J}$ & inu & uni & īju & unu & ano \\
\hline $\mathbf{k}$ & uki & iki & iku & uki & ək \\
\hline$x$ & uxi & ixi & ixu & uxu & - $\partial x \partial$ \\
\hline $\mathrm{g}$ & igu & igi & ugi & ugu & $\partial g \partial$ \\
\hline
\end{tabular}

TABEL VI. Volgorde van breed na smal.

Ook hier is geen konstante patroon uit te wys nie. Dit lyk of enige klankomgewing wat [i] bevat, verantwoordelik is vir die breedste laterale aanraking. Die smalste laterale aanraking word in die meeste gevalle veroorsaak deur die omgewing [ə-ə], gevolg deur [u-u].

Die ondersoek het baie duidelik getoon dat die grootste laterale aanraking voorkom by die frikatiewe $[s],\{z]$ en $[\delta]$. Indien die velêre klanke uitgesluit word, lyk dit of die ratelklank tesame met die tikklank gekenmerk word deur die kleinste laterale aanraking. Dit is ook opvallend dat hierdie twee klanke met besondere klein mediale aanrakings geartikuleer word.

Interessant van hierdie proefpersoon is dat artikulasiebewegings deurgaans ' $n$ besondere sterk neiging na regs toon. Hierdie patroon het egter geen hoorbare invloed op die akoestiese resultaat van die spraakproduksie nie. Die laterale neiging is duidelik waarneembaar in die onderste voorbeeldgrafieke van [s].

Die stabiliteit van die artikulasiekontakpunt in verskillende klankomgewings toon 'n wye variasie (Tabel IV). Die velêre klanke word hier buite rekening gelaat omdat moontlike verskuiwings van die area van aanraking na agter nie deur hierdie metode opgeteken kan word nie. Die volgorde van mees stabiel na minste stabiel verskyn in Tabel VII.

\begin{tabular}{|c|c|c|c|c|c|c|c|c|c|}
\hline & r & $\mathrm{s}$ & d & $t$ & 1 & $\mathrm{z}$ & $\mathbf{n}$ & 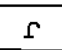 & $\int$ \\
\hline Standaard & 5,1 & 6,4 & 7,6 & 8,37 & 9 & 11,2 & 12,4 & 17,3 & 19,7 \\
\hline
\end{tabular}

TABEL VII. Volgorde van mees na minste stabiel t.o.v. area van artikulasiekontak.

\section{BESPREKING}

'n Ernstige tekortkoming van hierdie studie is dat slegs een proefpersoon daarby betrek kon word. Die metode is egter duur en omslagtig. Ten spyte van hierdie tekortkoming kan daar tog sekere nuttige aanwendings van die bevindings in terapie gemaak word. In terapie vir addentale artikulasie sou dit volgens hierdie gegewens sinvol wees om aanvanklik 
konsonant artikulasie in die [u-u] omgewing vas te lê, aangesien hierdie omgewing die kontakpunt na agter verskuif.

Die mate van motoriese vaardigheid en akkurate plasing wat vir die produksie van $[\mathrm{r}]$ vereis word, word beklemtoon deur die groot mate van stabiliteit van artikulasiekontakpunt en die besondere klein anteroposterior area van aanraking. In die geval van 'n persoon wat afsluitingsklanke met 'n breë stootbeweging artikuleer (hoewel die akoestiese resultaat vir klanke soos [ $t]$ en [d] bevredigend kan wees) sal 'n bevredigende $[\mathbf{r}]$ onwaarskynlik wees.

Die wisselende areas van aanraking vir die verskillende klankomgewings wys net weer op die noodsaaklikheid van 'n program waarin artikulasie van 'n klank in stelselmatig wisselende klankomgewings geoefen word. Dit geld by uitstek vir die $[\mathrm{n}]$ en die $\left[J^{\prime} \mid\right.$ (die $[\sigma]$, wat ook 'n groot mate van wisseling t.o.v. artikulasiekontakpunt openbaar, is nie 'n foneem in Afrikaans nie).

'n Interessante waarneming met betrekking tot $[\mathrm{n} \mid$ is dat hierdie klank wat in Afrikaans in 'n groot mate onderworpe is aan ko-artikulatoriese beïnloeding deur konsonante skynbaar ook in 'n groot mate deur vokale beïnvloed word.

Hierdie studie is in vele opsigte 'n ideale onderwerp vir meer gesofistikeerde bestudering met behulp van nuwe elektropalatografiese tegnieke. Aangesien hierdie tegniek nog nie in Suid-Afrika beskikbaar is nie, sal data wat bostaande bevindings verwerp of bevestig, waardevol wees.

\title{
Books on Speech and Hearing
}

\section{CONSULT}

\author{
CAMPUS BOOKSHOP .......... 34 Bertha Street, \\ P.O. Box 31361 \\ BRAAMFONTEIN 2017 \\ Telephone 39-1711
}

WESTDENE MEDIO BOOKS

35/6 Nedbank Plaza,

175 Beatrix Street

PRETORIA

Telephone 2-6336

LOGANS UNIVERSITY BOOKSHOP ... 227/9 Francois Road,
DURBAN
Telephone $35-4111$

Overseas publications obtained promptly. Nationwide mail-order service. 


\section{The IE-30A System from}

\section{Audio Analysis IVIE}

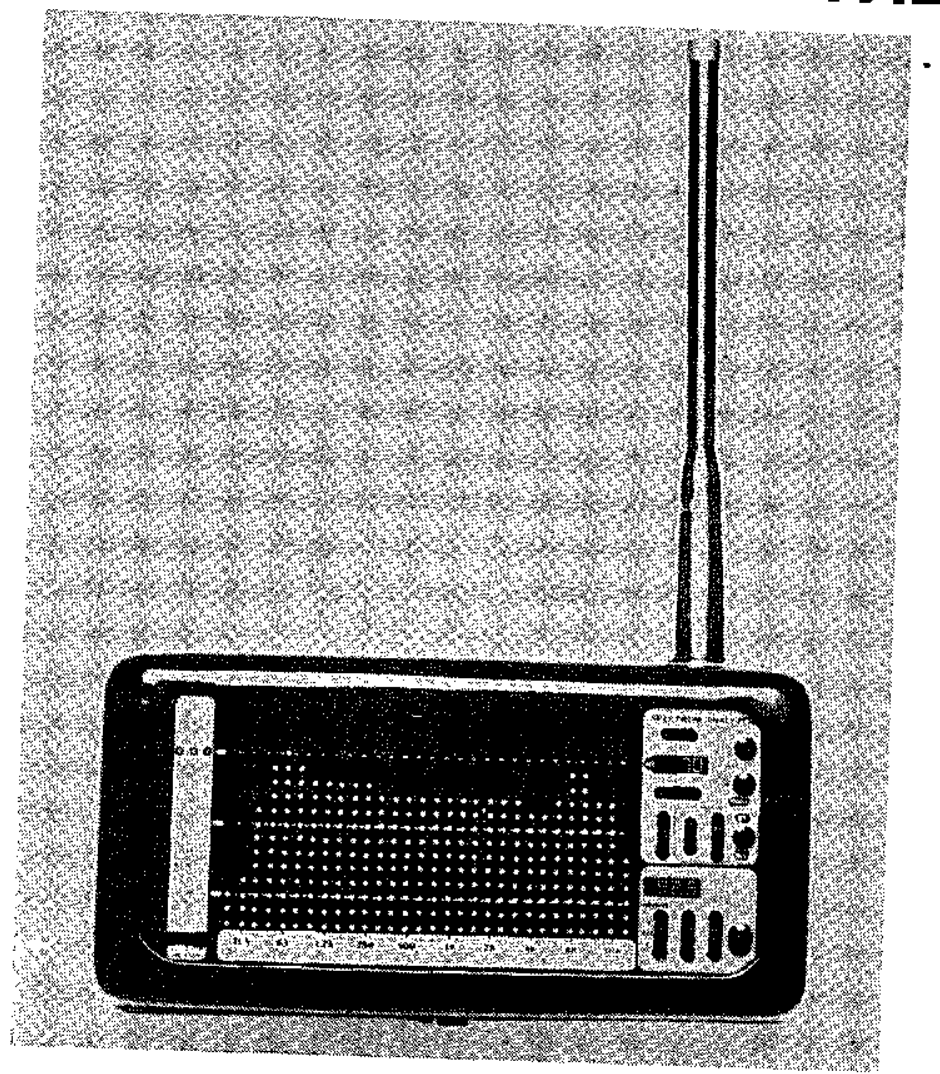

1) Instantaneously displays complete frequency spectrum of sounds,
voices, etc.

2) Portable, hand held, rechargeable battery or mains operated complete with precision microphone, battery charger and carrying case.

3) Two memories, individual store spectrum pattern.

4) May be used to generate voice prints.

5) Contains precision sound level meter with digital readout.

6) Output for oscilliscope, chart recorder, etc.

For further information contact:

\section{COLOSSEUM ACOUSTICS}

95, Kerk Street, Johannesburg. Phone 23-4541. 